\title{
Effects of sub-atmospheric pressure and dissolved oxygen concentration on lesions generated in ex vivo tissues by high intensity focused ultrasound
}

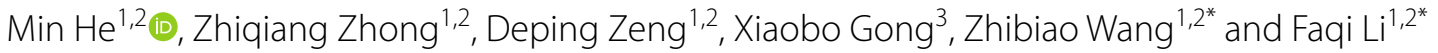

\author{
${ }^{*}$ Correspondence: \\ wangzb@cqmu.edu.cn; \\ lifq@cqmu.edu.cn \\ 1 State Key Laboratory \\ of Ultrasound in Medicine \\ and Engineering, \\ College of Biomedical \\ Engineering, Chongqing \\ Medical University, \\ Chongqing 400016, China \\ Full list of author information \\ is available at the end of the \\ article
}

\begin{abstract}
Background: Acoustic cavitation plays an important role in the medical treatment using high-intensity focused ultrasound (HIFU), but unnecessarily strong cavitation also could deform the morphology and enlarge the size of lesions. It is known that the increase of ambient hydrostatic pressure $\left(P_{\text {stat }}\right)$ can control the acoustic cavitation. But the question of how the decrease of $P_{\text {stat }}$ and dissolved oxygen concentration (DOC) influence the strength of cavitation has not been thoroughly answered. In this study, we aimed to investigate the relationship among the $P_{\text {stat, }} \mathrm{DOC}$ and the strength of cavitation.
\end{abstract}

Methods: Ex vivo bovine liver tissues were immersed in degassed water with different DOC of $1.0 \mathrm{mg} / \mathrm{L}, 1.5 \mathrm{mg} / \mathrm{L}$ and $2.0 \mathrm{mg} / \mathrm{L}$. Ultrasound (US) of $1 \mathrm{MHz}$ and the spatial and temporal average intensity $\left(I_{\text {sata }}\right)$ of $6500 \mathrm{~W} / \mathrm{cm}^{2}$ was used to expose two groups of in vitro bovine livers for $2 \mathrm{~s}$; one group was under atmospheric pressure $\left(P_{\text {stat }}=1\right.$ bar $)$ and the other was under sub-atmospheric pressure $\left(P_{\text {stat }}=0.1\right.$ bar $)$. Acoustic cavitation was detected by a passive cavitation detector (PCD) during the exposure process. Echo signals at the focal zone of HIFU were monitored by B-mode ultrasound imaging before and after exposure. The difference between two pressure groups was tested using paired sample $t$-test. The difference among different DOC groups was evaluated by one-way analysis of variance (ANOVA).

Results: The results demonstrated a significant difference of broadband acoustic emissions from the cavitation bubbles, echo signals on B-mode image, morphology of lesions under various conditions of ambient pressure and DOC. The lesion volume in tissue was increased with the increase of ambient pressure and DOC.

Conclusion: Cavitation could be suppressed through sub-atmospheric pressure and low DOC level in liver tissue, which could provide a method of controlling cavitation in HIFU treatment to avoid unpredictable lesions.

Keywords: HIFU, Cavitation, Lesion, Sub-atmospheric pressure, Dissolved oxygen concentration author(s) and the source, provide a link to the Creative Commons licence, and indicate if changes were made. The images or other third party material in this article are included in the article's Creative Commons licence, unless indicated otherwise in a credit line to the material. If material is not included in the article's Creative Commons licence and your intended use is not permitted by statutory regulation or exceeds the permitted use, you will need to obtain permission directly from the copyright holder. To view a copy of this licence, visit http:// creativecommons.org/licenses/by/4.0/. The Creative Commons Public Domain Dedication waiver (http://creativecommons.org/publi cdomain/zero/1.0/) applies to the data made available in this article, unless otherwise stated in a credit line to the data. 


\section{Background}

As a noninvasive therapy for cancer treatment, high-intensity focused ultrasound (HIFU) has recently been receiving more and more attention [1-4]. The absorption of highly localized ultrasound energy by the targeted tissue in the focal region allows the temperature in situ rapidly rise over $60{ }^{\circ} \mathrm{C}$, consequently the irreversible coagulation necrosis takes place instantaneously [5-7], while the surrounding tissues are spared from the significant damage [8]. During HIFU treatment, acoustic cavitation plays an important role through the collapse of oscillating microbubbles in tissues $[9,10]$. Cavitation enhances lesion formation mainly by local high-intensity acoustic wave, thermal deposition of acoustic radiation from the compressed bubbles and the viscous loss of bubble oscillation through tissue organization and the body liquid [11-13]. Coussios et al. [14] indicated that the appearance of cavitation bubbles would change the acoustic impedance and attenuation coefficient, resulting in more severe lesion. Chen et al. [15] and Watkin et al. [16] found that the morphology and size of targeted tissue were out of control due to severe cavitation. Sokka et al. [17] observed that lesions with cavitation in the region closer to the transducer of thigh tissue of rabbit were about $2 \sim 3$ times larger by volume than the lesions under the same exposure conditions without cavitation. Hynynen [18] showed that an enhanced heating effect in dog's thigh tissue during sonications, and concluded that such effect should be avoided in clinical therapy because they might lead to unpredictable thermal and mechanical damage. Chapelon et al. [19-21] observed irregular lesion outside the focal zone when uncontrolled cavitation occurred during HIFU treatment, which affected the therapeutic effects of targeted tissue. They strongly recommended that acoustic cavitation during the treatment should be avoided.

Cyril et al. [22] showed that using gated sonication instead of continuous sonications can remove residual cavitation nuclei between pulses with gated sonications to weaken the cavitation. Several researchers elevated the ambient hydrostatic pressure $\left(P_{\text {stat }}\right)$ to suppress cavitation [23-25] in continuous HIFU treatment. He et al. [26] proved that elevating the ambient hydrostatic pressure can restrain the acoustic cavitation, the morphology of lesion was regular and the size was smaller under higher $P_{\text {stat }}$. Caupin and Herbert [27] demonstrated that cavitation threshold would increase with the increase of hydrostatic pressure, but sub-atmospheric pressure would strengthen the process of expansion motion of microbubbles and promote the activities of cavitation bubbles. After systematic experiment and molecular dynamics simulations, Kinjo and Matsumoto [28] manifested that cavitation nuclei would appear immediately under the condition of a sub-atmospheric pressure of 0.2 bar, and the appearance time would be delayed when under sub-atmospheric pressure with $P_{\text {stat }}$ equal to 0.4 bar. However, all these studies were all performed in water. It is still unknown whether the sub-atmospheric pressure would influence cavitation activities in biological tissues such as the liver during the process of HIFU exposure.

Dissolved oxygen concentration (DOC) also plays a significant role on the cavitation bubble during HIFU treatment. A change in the gas content of a medium can affect the propagation of focused ultrasound beam, leading to an unpredictable lesion. Saito and Soetanto [29] showed that the quantity of microbubbles would increase with the increase of DOC during ultrasound irradiation. Tuziuti et al. [30] indicated that cavitation was 
more active as the increase of DOC in a solution. Stomach and intestinal preparation including fasting and water-deprivation were necessary before the clinical treatment of liver cancer, pancreatic cancer and kidney cancer [31-33]. When treating prostate cancer and uterine fibroid, and bladder injection with degassed water as acoustic coupling medium through the catheter was also needed $[34,35]$, and the DOC of degassed water should be less than $4 \mathrm{mg} / \mathrm{L}$, according to the treatment standard issued by the State Food \& Drug Administration of China [36]. In HIFU experiments, isolated biological tissues such as bovine liver were generally degassed for $1 \mathrm{~h}$ [37]. However, the value of DOC in bovine liver tissue was not clearly stated in literature.

Based on these findings, we hypothesized that $P_{\text {stat }}$ and DOC can control the cavitation in tissue during HIFU treatment. Thus, in the present study, we examined whether $P_{\text {stat }}$ and DOC can regulate the lesion morphology and smaller the lesion size induced by cavitation in HIFU treatment. And if so, to analyze the mechanism of lesion formation and cavitation behavior in ex vivo bovine livers.

\section{Results}

\section{DOC in degassed water and inside the tissue}

Table 1 shows the DOC of degassed water and inside the tissue. Under the three levels of DOC $(1.0 \mathrm{mg} / \mathrm{L}, 1.5 \mathrm{mg} / \mathrm{L}, 2.0 \mathrm{mg} / \mathrm{L})$, there is no significant difference between the DOC in degassed water and inside the water. Because of the DOC test inside the tissue took much more time than the test in water, we used the DOC in water to present the DOC inside the tissue.

\section{Cavitation signal}

Under the conditions of atmospheric pressure and sub-atmospheric pressure, the broadband emissions from ex vivo bovine liver exposed by HIFU in degassed water

Table 1 The comparison of DOC in degassed water and inside the tissue

\begin{tabular}{|c|c|c|c|c|c|}
\hline $\begin{array}{l}\text { Dissolved oxygen } \\
\text { concentration } \\
\text { (mg/L) }\end{array}$ & $\begin{array}{l}\text { Test in } \\
\text { degassed } \\
\text { water }(\mathrm{mg} / \mathrm{L})\end{array}$ & $\begin{array}{l}\text { Mean value in } \\
\text { degassed water } \\
(\mathrm{mg} / \mathrm{L})\end{array}$ & $\begin{array}{l}\text { Test in } \\
\text { tissue } \\
\text { (mg/L) }\end{array}$ & $\begin{array}{l}\text { Mean value } \\
\text { in tissue } \\
(\mathrm{mg} / \mathrm{L})\end{array}$ & $\begin{array}{l}\text { Rate of deviation } \\
\text { between water and } \\
\text { tissue (\%) }\end{array}$ \\
\hline \multirow[t]{5}{*}{1.0} & 1.07 & 1.04 & 0.95 & 1.05 & 0.77 \\
\hline & 0.99 & & 1.06 & & \\
\hline & 1.05 & & 1.03 & & \\
\hline & 0.98 & & 1.10 & & \\
\hline & 1.10 & & 1.08 & & \\
\hline \multirow[t]{5}{*}{1.5} & 1.48 & 1.52 & 1.53 & 1.54 & 1.45 \\
\hline & 1.40 & & 1.57 & & \\
\hline & 1.52 & & 1.46 & & \\
\hline & 1.60 & & 1.61 & & \\
\hline & 1.58 & & 1.52 & & \\
\hline \multirow[t]{5}{*}{2.0} & 1.98 & 2.02 & 2.10 & 2.03 & 0.40 \\
\hline & 2.06 & & 2.03 & & \\
\hline & 2.00 & & 1.95 & & \\
\hline & 1.98 & & 2.09 & & \\
\hline & 2.09 & & 1.98 & & \\
\hline
\end{tabular}



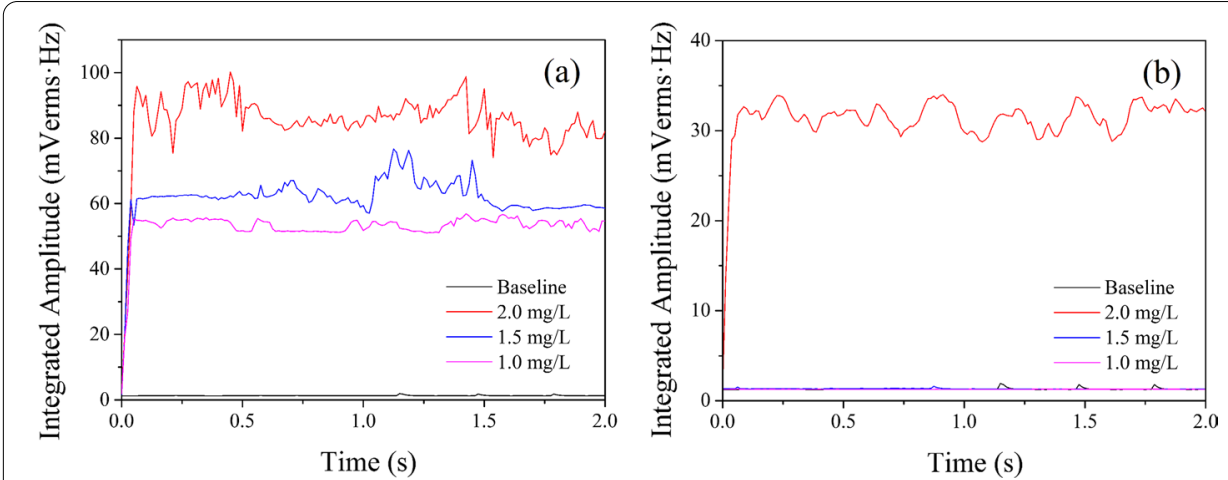

Fig. 1 Broadband noise during HIFU exposure: a atmospheric pressure, $\mathbf{b}$ sub-atmospheric pressure. The black solid line was the baseline detected without HIFU exposure. The red, blue and purple solid lines represent the broadband noise signal at the DOC of $2.0 \mathrm{mg} / \mathrm{L}, 1.5 \mathrm{mg} / \mathrm{L}$ and $1.0 \mathrm{mg} / \mathrm{L}$, respectively

\begin{tabular}{l}
$\begin{array}{l}\text { Dissolved oxygen } \\
\text { concentration: }\end{array}$ \\
\hline $\begin{array}{c}\text { Atmospheric } \\
\text { pressure }\end{array}$ \\
$\begin{array}{l}\text { Sub-atmospheric } \\
\text { pressure }\end{array}$ \\
$\begin{array}{l}\text { Fig. } 2 \text { B-mode ultrasound image before and after HIFU exposure. The white dotted circle flagged the HIFU } \\
\text { focus zone. Hyper-echoic occurred under all conditions except at sub-atmospheric pressure with the DOC of } \\
1.0 \mathrm{mg} / \mathrm{L}\end{array}$
\end{tabular}

with different DOC are shown in Fig. 1. The black solid line was the baseline which was detected without HIFU exposure. The signals of broadband emissions under atmospheric pressure (Fig. 1a) were higher than that under sub-atmospheric pressure (Fig. 1b) when DOC was the same. Under the condition of atmospheric pressure $(1 \mathrm{bar})$, the signal of broadband emissions at three DOC levels $(1.0 \mathrm{mg} / \mathrm{L}, 1.5 \mathrm{mg} / \mathrm{L}$ and $2.0 \mathrm{mg} / \mathrm{L})$ were all above the noise level of the system during HIFU exposure. Moreover, the signal of broadband noise increased with an increase of the DOC levels. Under the condition of sub-atmospheric pressure ( $0.1 \mathrm{bar})$, there was no signal of broadband emissions above the noise level of the system except under DOC of $2.0 \mathrm{mg} / \mathrm{L}$. The violent collapse of transient cavitation is the only source of broadband emissions [15], these results indicated that each DOC level had transient cavitation behavior during HIFU exposure under atmospheric pressure, but under the condition of sub-atmospheric pressure, only $2.0 \mathrm{mg} / \mathrm{L}$ had transient cavitation behavior.

\section{Gray-level variation on B-mode ultrasound}

Figure 2 shows B-mode ultrasound image change before and after HIFU exposure. HIFU focus was located in the center of white dotted circle during the exposure. Under the condition of atmospheric pressure (1 bar), hyper-echoic change was found in the focus 
after HIFU exposure under the condition of different DOC levels. Under sub-atmospheric pressure (0.1 bar), hyper-echoic changes were observed found under DOC conditions of $1.5 \mathrm{mg} / \mathrm{L}$ and $2.0 \mathrm{mg} / \mathrm{L}$, but no hyper-echo at $1.0 \mathrm{mg} / \mathrm{L} \mathrm{DOC}$.

\section{Lesions on ex vivo bovine livers}

The morphology of lesions in ex vivo bovine liver exposed by HIFU is shown in Fig. 3. Under atmospheric pressure ( $1 \mathrm{bar}$ ), the morphology of lesions was very different from each other. In the $2.0 \mathrm{mg} / \mathrm{L}$ DOC group, the lesion was teardrop-shaped. In the $1.5 \mathrm{mg} / \mathrm{L}$ and $1.0 \mathrm{mg} / \mathrm{L}$ DOC groups, the lesions were approximately ellipsoidal. Under sub-atmospheric pressure ( $0.1 \mathrm{bar})$, in the $2.0 \mathrm{mg} / \mathrm{L}$ DOC group, the lesion was approximately cigar-shaped. In the $1.5 \mathrm{mg} / \mathrm{L}$ DOC group, the lesion was also cigar-shaped, but the size of lesion was smaller than that in the $2.0 \mathrm{mg} / \mathrm{L}$ group, with homogeneous coagulation necrosis in the central part. In the $1.0 \mathrm{mg} / \mathrm{L}$ DOC group there was no significant lesion formed in the liver tissue. In addition, when the DOC level was the same, the size of lesions at atmospheric pressure ( 1 bar) were larger than that at sub-atmospheric pressure $(0.1 \mathrm{bar})$, and damage on the central zone of lesion at atmospheric pressure ( $1 \mathrm{bar})$ was severer than that at sub-atmospheric pressure ( 0.1 bar).

Figure 4 shows the volume of lesions in ex vivo bovine liver exposed by HIFU under atmospheric pressure (1 bar) and sub-atmospheric pressure $(0.1 \mathrm{bar})$ with different DOC conditions. At atmospheric pressure (1 bar), the volume of lesions in the $2.0 \mathrm{mg} / \mathrm{L}$ and $1.5 \mathrm{mg} / \mathrm{L}$ DOC group were $83.28 \pm 14.56 \mathrm{~mm}^{3}$ and $76.84 \pm 11.07 \mathrm{~mm}^{3}$, respectively. There was no significant difference between two groups $(p>0.05)$. However, when DOC

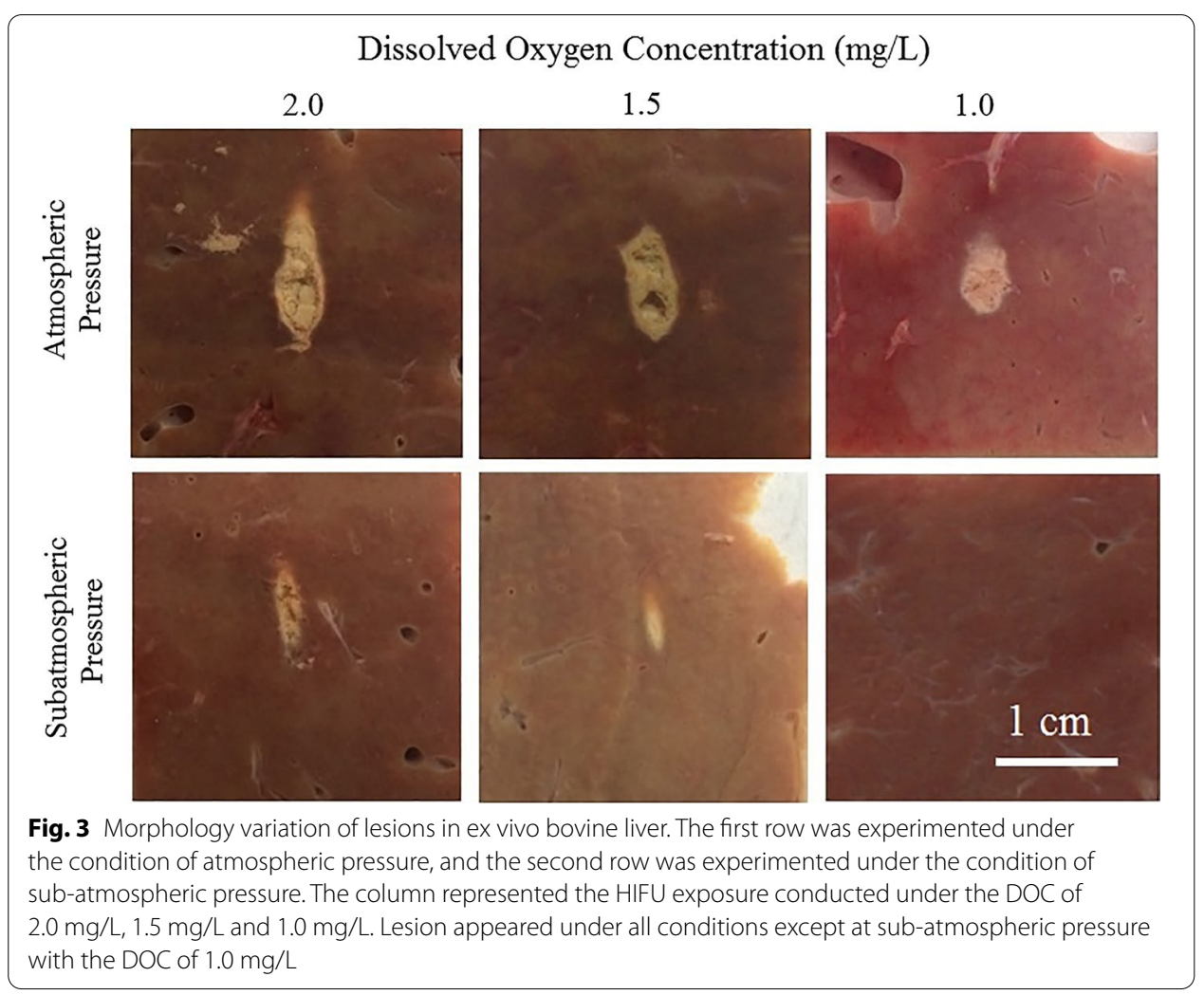




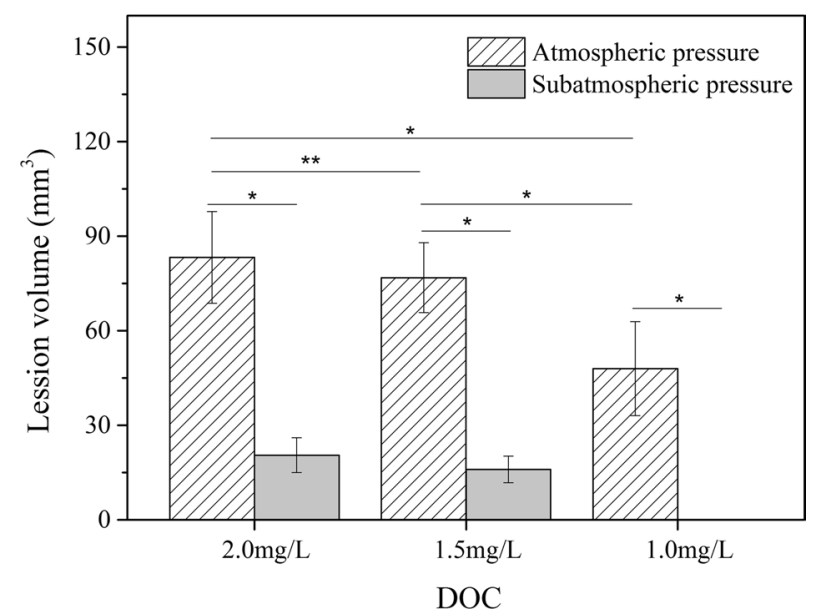

Fig. 4 Lesion volume variation in ex vivo bovine liver after HIFU exposure. At atmospheric pressure (1 bar), the volume of lesions in the $2.0 \mathrm{mg} / \mathrm{L}$ and $1.5 \mathrm{mg} / \mathrm{L} \mathrm{DOC} \mathrm{group} \mathrm{were} 83.28 \pm 14.56 \mathrm{~mm}^{3}$ and $76.84 \pm 11.07 \mathrm{~mm}^{3}$, respectively. At sub-atmospheric pressure $(0.1 \mathrm{bar})$, the volume of lesions in the $2.0 \mathrm{mg} / \mathrm{L}$, $1.5 \mathrm{mg} / \mathrm{L}$ and $1.0 \mathrm{mg} / \mathrm{L}$ groups were $20.53 \pm 5.54 \mathrm{~mm}^{3}, 16.01 \pm 4.22 \mathrm{~mm}^{3}$ and $0.00 \pm 0.00 \mathrm{~mm}^{3}$, respectively. Lesion volume under atmospheric pressure was significantly different from that under sub-atmospheric pressure when DOC was kept the same. *Represents $p<0.05$ for significance of difference between the two groups, ${ }^{* *}$ represents $p>0.05$ for no significance of difference between the two groups

was equal to $1.0 \mathrm{mg} / \mathrm{L}$, the volume of lesion was $47.98 \pm 14.92 \mathrm{~mm}^{3}$, which was significantly decreased while compared with the $2.0 \mathrm{mg} / \mathrm{L}$ and $1.5 \mathrm{mg} / \mathrm{L}$ groups $(p<0.05)$. At sub-atmospheric pressure ( $0.1 \mathrm{bar})$, the volume of lesions in the $2.0 \mathrm{mg} / \mathrm{L}, 1.5 \mathrm{mg} / \mathrm{L}$ and $1.0 \mathrm{mg} / \mathrm{L}$ groups were $20.53 \pm 5.54 \mathrm{~mm}^{3}, 16.01 \pm 4.22 \mathrm{~mm}^{3}$ and $0.00 \pm 0.00 \mathrm{~mm}^{3}$, respectively. There were significant differences between any two $(p<0.05)$, indicating that the volume of lesion was increased with the increase of DOC levels at either atmospheric pressure or sub-atmospheric pressure. Meanwhile, the volume of lesion in tissue at atmospheric pressure ( $1 \mathrm{bar})$ was larger than that at sub-atmospheric pressure $(0.1 \mathrm{bar})$ while DOC level kept the same $(p<0.05)$.

\section{Discussion}

The main mechanisms of coagulation necrosis induced by HIFU are thermal deposition and cavitation effect [38]. During the process of HIFU exposure, the absorption of sound energy can result in thermal deposition in tissue, leading to formation of lesions [6]. Moreover, cavitation can accelerate the rise of the in situ temperature and enlarge the size of lesions [18]. Cavitation includes stable cavitation and transient cavitation [39], and the accelerated temperature increasing during HIFU exposure comes from transient cavitation [17].

Overpressure has been proved to suppress cavitation and has been used to study the influence of cavitation on HIFU-induced lesions [24-26]. This study investigates the effect of atmospheric pressure and sub-atmospheric pressure on the formation of the lesions. Under various DOC conditions $(2.0 \mathrm{mg} / \mathrm{L}, 1.5 \mathrm{mg} / \mathrm{L}$ or $1.0 \mathrm{mg} / \mathrm{L})$, the broadband noise at sub-atmospheric pressure $(0.1 \mathrm{bar})$ is significantly lower than that at atmospheric pressure (1 bar). It manifests that sub-atmospheric pressure can partly suppress cavitation in liver tissue during HIFU exposure, which is different from the report that sub-atmospheric pressure can strengthen cavitation activity in 
water by Caupin and Herbert [27]. We think that although sub-atmospheric pressure can enhance the expansion process of cavitation bubble, the mechanical strain of sub-atmospheric pressure can also disperse the bubble distribution in tissue, resulting in that cavitation bubble cannot stably form and concentrate in the focus and the signal of sound scattering in focus is distinctly weakened. This is demonstrated by our bovine liver experiments at sub-atmospheric pressure, which reveals that the volume of the lesions is smaller than that at atmospheric pressure $(p<0.05)$. Under the experiment parameter under which cavitation occurred, the center of lesions appears to be mechanically damaged due to the collapse of cavitation bubbles. Without cavitation occurring, the lesion undergoes homogeneous necrosis, and there is no lesion formed in bovine liver tissue while DOC is equal to $1.0 \mathrm{mg} / \mathrm{L}$.

This study also demonstrates a certain quantity of cavitation nuclei is needed for the occurrence of cavitation. Under atmospheric pressure, PCD results showed that cavitation activities exist during HIFU exposure under the condition of three DOC levels, with the hyper-echoic changed observed on B-mode ultrasound after HIFU exposure. With the increase of DOC level, the strength of the cavitation signal enhances gradually during the process of exposure, leading to the increased volume of the lesion in bovine liver tissue. However, under sub-atmospheric pressure, cavitation signal only appeared in $2.0 \mathrm{mg} / \mathrm{L}$ DOC level group, and the B-mode ultrasound image without hyper-echoic occurred only at the DOC $1.0 \mathrm{mg} / \mathrm{L}$ group. The volume of the lesion at the condition of $2.0 \mathrm{mg} / \mathrm{L}$ DOC is $20.53 \pm 5.54 \mathrm{~mm}^{3}$, which is larger than the lesion volume of $16.01 \pm 4.22 \mathrm{~mm}^{3}$ at the DOC $1.5 \mathrm{mg} / \mathrm{L}$ group $(p<0.05)$, but no lesion is observed at the DOC $1.0 \mathrm{mg} / \mathrm{L}$ group, indicating that lower DOC level could produce less gas content in water, and less than the critical number of cavitation nuclei that makes cavitation difficult occur during HIFU exposure. On the contrary, an increase of gas content in both water and tissues could facilitate the occurrence of cavitation and lesion formation, which could improve the efficiency of HIFU treatment through microbubbles [40]. In addition, Rabkin et al. [41] reported that hyper-echo on B-mode ultrasound was produced by boiling bubbles of water during HIFU exposure. But the boiling point of water at sub-atmospheric pressure $(0.1 \mathrm{bar})$ is only $56{ }^{\circ} \mathrm{C}$, which is much lower than that at atmospheric pressure (1 bar). This might help understand our findings that under the condition of sub-atmospheric pressure and DOC $1.5 \mathrm{mg} / \mathrm{L}$ level, PCD showed no cavitation during HIFU exposure but a significant hyper-echo on B-mode ultrasound and homogenous lesion in bovine liver tissue.

\section{Conclusions}

Using ex vivo bovine livers, we investigated the effect of $P_{\text {stat }}$ and DOC levels on the formation of HIFU-induced lesions in this study. Our results showed that the occurrence of cavitation could be suppressed through sub-atmospheric pressure and low DOC level in liver tissue. This could provide a method of controlling cavitation in HIFU treatment which could avoid unpredictable lesions. Conversely, coagulation necrosis could be enhanced by increasing the quantity of cavitation nuclei in tissues. 


\section{Methods}

As shown in Fig. 5, the experiment is mainly composed of three parts: the preparatory work, the HIFU exposure and the data analysis. The preparatory work and the HIFU exposure experiment were performed in a stainless chamber $(50 \mathrm{~cm}$ $L \times 50 \mathrm{~cm} \mathrm{~W} \times 70 \mathrm{~cm} H$ ) which was filled with degassed water. The data analysis was carried out on the computer.

\section{Experimental equipment}

As shown in Fig. 6, the major experimental system (Jisheng 1\#, Chongqing Haifu Technology Co., Ltd, Chongqing, China) includes a $1.0 \mathrm{MHz}$ HIFU transducer (12-32, Chongqing Haifu Technology Co., Ltd, Chongqing, China), with an aperture diameter of $220 \mathrm{~mm}$ and a focal length of $170 \mathrm{~mm}$. The probe of the B-mode ultrasound (PA230E, ESAOTE Co., Genova, Italy) was mounted in the central hole of HIFU transducer, sharing the same focus with HIFU transducer, so that its imaging plane intersected the HIFU axis along its axial length. Data cables connected to a computer through the hermetic feedthrough. A HIFU drive system, a water processing system, which can prepare for degassed water of different DOC, and sample holder are all provided by Chongqing Haifu (HIFU) Technology Co., Ltd. A rotary vane vacuum pump (2XZ-2, Taizhou Qiushi vacuum pump Co., Ltd, Zhejiang, China) was used to control the condition of $P_{\text {stat }}$ in the chamber. DOC in water and tissue was monitored by a portable dissolved oxygen

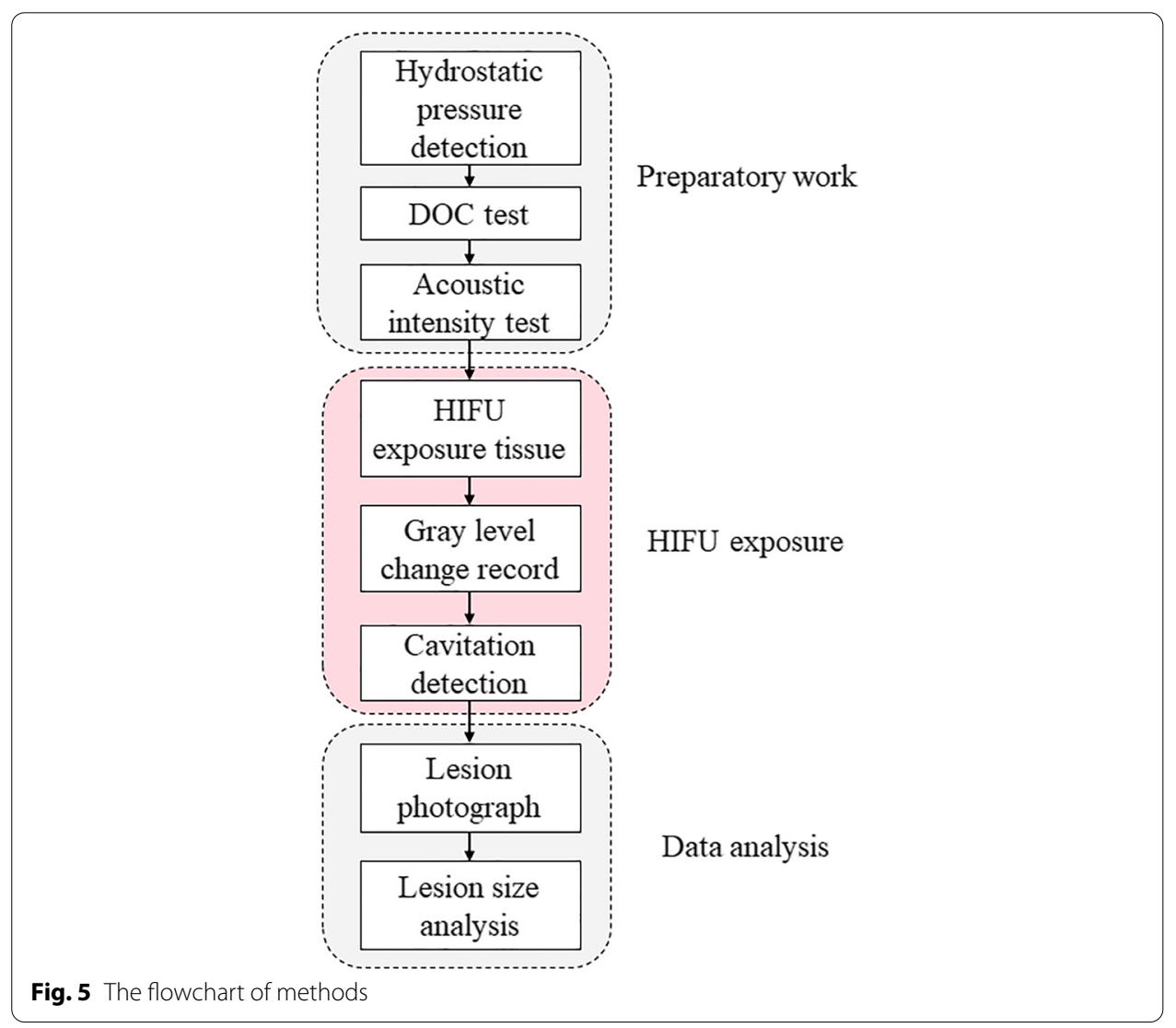




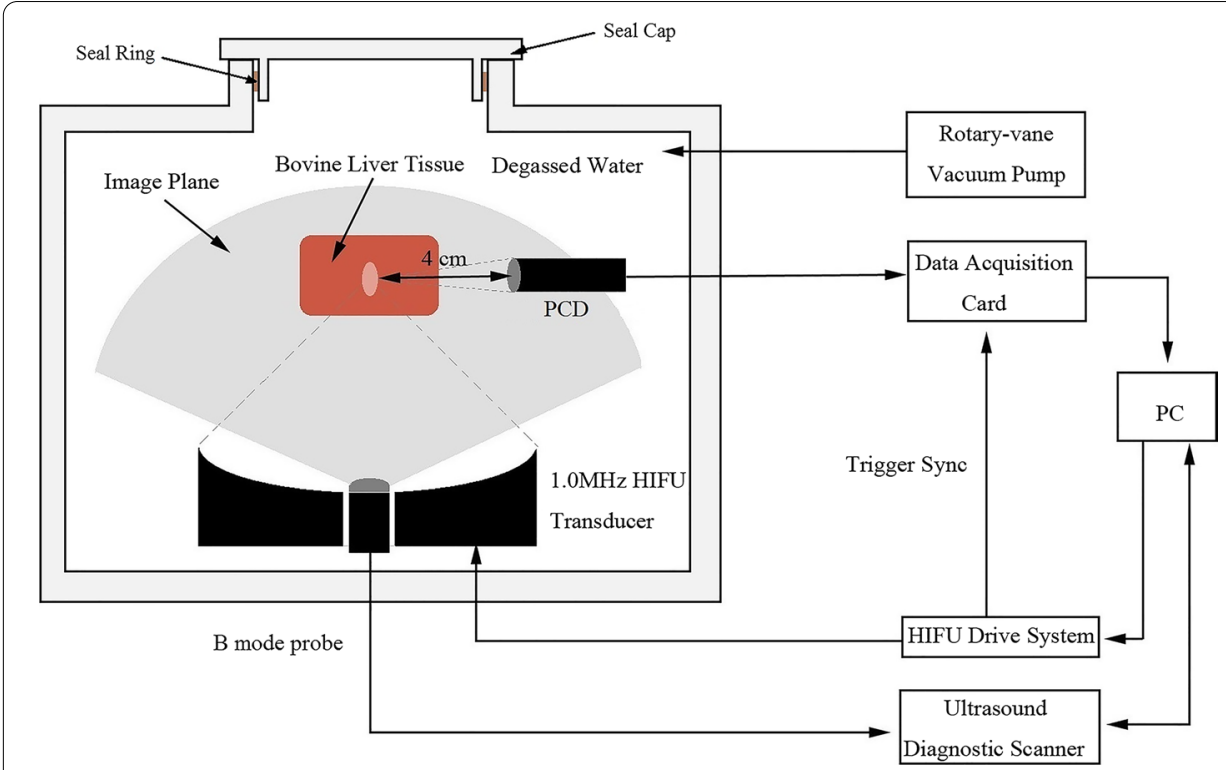

Fig. 6 Schematic diagram of the experimental system. The HIFU transducer was driven by the HIFU drive system. The input power was set on the PC. The PCD signal was acquired by the data acquisition card and shown on the PC. The ultrasound diagnostic scanner, which was controlled by PC, was used to scan the B-mode image of tissue

meter (LDOTM 550A-12, YSI Co., Yellow Springs, OH, USA), with measurement range of $0 \sim 50 \mathrm{mg} / \mathrm{L}$ and resolution of $0.01 \mathrm{mg} / \mathrm{L}$.

\section{Dissolved oxygen concentration and hydrostatic pressure detection}

Degassed water at different DOC levels was prepared by regulating the water flow of a water processing system. The experimental chamber was filled with degassed water at DOC of $1.0 \mathrm{mg} / \mathrm{L}, 1.5 \mathrm{mg} / \mathrm{L}$ and $2.0 \mathrm{mg} / \mathrm{L}$, respectively, with the temperature kept at $37^{\circ} \mathrm{C}$, according to the standard protocol of HIFU treatment system [36]. The degassed bovine liver specimens were mounted in the sample holder, and then placed in the experimental chamber. Ten minutes later, the DOC of degassed water and inside the tissue was detected for five times, shown in Table 1. The DOC in water was in accord with the DOC inside the tissue. Therefore, we used the DOC in water to present the DOC inside the tissue. $P_{\text {stat }}$ in sealed experimental chamber was changed by a vacuum pump which was turned off after 5 min to keep the experimental chamber under the $P_{\text {stat }}$ of 0.1 bar, which was the maximum negative pressure that vacuum pump could stably support.

\section{Acoustic intensity test}

Acoustic spatial and temporal averaged intensity $\left(I_{\text {sata }}\right)$ was $6500 \mathrm{~W} / \mathrm{cm}^{2}$ for ultrasound applied to ex vivo bovine livers, where cavitation could be detected clearly under atmospheric pressure. Before the exposure experiment, the acoustic power generated was measured by the radiation force method [42], and the sound field was scanned by needle-type hydrophone (HFO-660, ONDA, Sunnyvale, CA, USA), in order to ensure every experiment had the same acoustic output. 


\section{HIFU exposure}

The liver specimens were taken from the portion of fresh bovine liver with less connective tissues and blood vessels within $6 \mathrm{~h}$ after the animal was killed. It was then cut into blocks of $12 \mathrm{~cm} \times 6 \mathrm{~cm} \times 4 \mathrm{~cm}$, soaked in $0.9 \%$ saline, and degassed by vacuum pump for $60 \mathrm{~min}$. During the experiment, 1-MHz HIFU transducer was used to generate a continuous wave of exposure parameter of $I_{\text {sata }} 6500 \mathrm{~W} / \mathrm{cm}^{2}$ for $2 \mathrm{~s}$ to expose bovine liver specimens. Experiments were done under two $P_{\text {stat }}:$ atmospheric pressure $\left(P_{\text {stat }}=1\right.$ bar $)$ and sub-atmospheric pressure $\left(P_{\text {stat }}=0.1\right.$ bar $)$. Experiments with same exposure conditions were repeated ten times. The gray-level variation of bovine livers at HIFU focus was monitored by B-mode ultrasound before and after HIFU exposure. Moreover, the DOC of water was detected by the portable dissolved oxygen analyzer before and after each experiment. The deviation of DOC in each group was within $\pm 0.1 \mathrm{mg} / \mathrm{L}$.

\section{Cavitation detection}

A passive cavitation detection (PCD) (V309-SU, Olympus Panametrics NDT Inc, Waltham, MA, USA) with a central frequency of $5 \mathrm{MHz}$ was used to detect the cavitation characteristics to compare the cavitation behavior. The broadband focusing PCD transducer with the diameter of $13 \mathrm{~mm}$ and focal length of $40 \mathrm{~mm}$ was fixed on the sample holder, shown in Fig. 6. Acoustic signal from ex vivo bovine liver was recorded by the high-speed data acquisition card with sampling rate of $20 \mathrm{MHz}$ (PXie-5122, National Instruments Co., USA). The corresponding spectrum of obtained signal was analyzed via fast Fourier transform on the LabView development platform (v10.0.1, National Instruments Co., Austin, TX, USA), and the sampling step length was $15 \mathrm{~ms}$. The broadband noise was calculated after band-pass filter $(3 \sim 7 \mathrm{MHz})$ and band-stop filter (filter stopped the signals around harmonics $\pm 30 \mathrm{kHz}$ ), to minimize the error caused by the contributions from the HIFU fundamental, second, third and fourth harmonic frequencies arising from nonlinear sound propagation.

\section{Data analysis}

Sections of the bovine liver specimens with their cross section perpendicular to the direction of acoustic propagation of HIFU were cut immediately after exposure to observe the lesion size and shape. The lesion was photographed digitally under every exposure condition. The HIFU measurement software (1.0, Chongqing Haifu Technology Co., Ltd, Chongqing, China) was used to set the scale and mark the boundary of the lesion region.

\section{Statistics analysis}

The SPSS software (19.0, IBM, Camp Takajo, NY, USA) was used for statistical analysis. The final measurement results were expressed by mean \pm standard deviation (SD). Difference between the sub-atmospheric pressure group and the atmospheric group was tested using paired sample $t$-test. Statistical relationships among the three DOC groups were evaluated by one-way analysis of variance (ANOVA), and Tukey's test was used for pairwise multiple comparisons if one-way ANOVA revealed statistical significance. A value of $p<0.05$ was accepted as statistically significant. 
Abbreviations

DOC: Dissolved oxygen concentration;; HIFU: High-intensity focused ultrasound; PCD: Passive cavitation detection; $P_{\text {stat: }}$ Ambient hydrostatic pressure.

\section{Acknowledgements}

Not applicable.

\section{Authors' contributions}

$\mathrm{MH}, \mathrm{FL}$ and ZW designed the study. MH and ZZ performed the experiments, collected and processed the data. XG and DZ maintained the experimental setup. MH wrote the manuscript. FL revised the manuscript. All authors read and approved the final manuscript.

\section{Funding}

This study was supported by the National Natural Science Foundation of China (Grant Nos. 81127901, 11274404, 11574039), and the State Key Development Program for Basic Research of China (973 program, Grant No. 2011CB707900)

\section{Availability of data and materials}

The datasets used and/or analyzed during the current study are available from the corresponding author on reasonable request.

\section{Declarations}

Ethics approval and consent to participate

Not applicable.

\section{Consent for publication}

Not applicable.

\section{Competing interests}

The authors declare that they have no competing interests.

\section{Author details}

${ }^{1}$ State Key Laboratory of Ultrasound in Medicine and Engineering, College of Biomedical Engineering, Chongqing Medical University, Chongqing 400016, China. ${ }^{2}$ Chongqing Key Laboratory of Biomedical Engineering, Chongqing Medical University, Chongqing 400016, China. ${ }^{3}$ National Engineering Research Center of Ultrasound Medicine, Chongqing 401121, People's Republic of China.

Received: 19 November 2020 Accepted: 28 August 2021

Published online: 15 September 2021

\section{References}

1. Wei F, Chen W, Lin X. HIFU ablation as a therapy for breast tumor: a meta-analysis of 23 prospective feasibility studies. Breast J. 2020:26:1478-80.

2. Bruno F, Catalucci A, Arrigoni F, et al. An experience-based review of HIFU in functional interventional neuroradiology: transcranial MRgFUS thalamotomy for treatment of tremor. Radiol Med. 2020;125:877-86.

3. Wang X, Geng Y, Han D, et al. Viscoelastic characterization of HIFU ablation with shear wave by using K-space analysis combined with model-fitting correction method. Ultrasonics. 2020;108:106179.

4. Marinova M, Wilhelm-Buchstab T, Strunk H. Advanced pancreatic cancer: high-intensity focused ultrasound (HIFU) and other local ablative therapies. Rofo. 2019;191:216-27.

5. Halpern EJ. High-intensity focused ultrasound ablation: will image-guided therapy replace conventional surgery? Radiology. 2005;235:345-6.

6. Hill CR, ter Haar GR. Review article: high intensity focused ultrasound-potential for cancer treatment. Br J Radiol. 1995;68:1296-303.

7. Wang M, Lei Y, Zhou Y. High-intensity focused ultrasound (HIFU) ablation by the frequency chirps: enhanced thermal field and cavitation at the focus. Ultrasonics. 2019;91:134-49.

8. Ko EJ, Hong JY, Kwon TR, et al. Efficacy and safety of non-invasive body tightening with high-intensity focused ultrasound (HIFU). Skin Res Technol. 2017;23:558-62.

9. Ter Harr G, Daniels S, Morton K. Evidence for acoustic cavitation in vivo: thresholds for bubble formation with 0.75 $\mathrm{MHz}$ continuous wave and pulsed beams. IEEE Trans Ultrason Ferroelectr Freq Control. 1986;33:162-4.

10. Holt G, Roy RA. Measurements of bubble-enhanced heating from focused, MHz-frequency ultrasound in a tissuemimicking material. Ultrasound Med Biol. 2001;27:1399-412.

11. Stride $E$, Saffari $N$. The potential for thermal damage posed by microbubble ultrasound contrast agents. Ultrasonics. 2004:42:907-13.

12. Sboros V. Response of contrast agents to ultrasound. Adv Drug Deliv Rev. 2008;60:1117.

13. Wan M, Feng Y, Haar GT. Cavitation in biomedicine. Netherlands: Springer; 2015.

14. Coussios CC, Farny $\mathrm{CH}$, Ter Haar G, et al. Role of acoustic cavitation in the delivery and monitoring of cancer treatment by high-intensity focused ultrasound (HIFU). Int J Hyperthermia. 2007;23:105-20. 
15. Chen WS, Brayman AA, Matula TJ, et al. Inertial cavitation dose and hemolysis produced in vitro with or without Optison. Ultrasound Med Biol. 2003;29:725-37.

16. Watkin $\mathrm{N}$, Ter Haar G, Rivens I. The intensity dependence of the site of maximal energy deposition in focused ultrasound surgery. Ultrasound Med Biol. 1996;22:483-91.

17. Sokka SD, King RK. MRI-guided gas bubble enhanced ultrasound heating in in vivo rabbit thigh. Phys Med Biol. 2003:48:223.

18. Hynynen K. The threshold for thermally significant cavitation in dog's thigh muscle in vivo. Ultrasound Med Biol. 1991;17:157-69.

19. Chapelon JY, Prat F, Delon C, et al. Effects of cavitation in the high intensity therapeutic ultrasound. In Ultrasonics Symposium, 1991. Proceedings., IEEE. 1991;2:1357-60.

20. Chapelon JY, Dupenloup F, Cohen H, et al. Reduction of cavitation using pseudorandom signals [therapeutic US]. IEEE Trans Ultrason Ferroelectr Freq Control. 1996;43:623-5.

21. Chapelon JY, Cathignol D, Cain C, et al. New piezoelectric transducers for therapeutic ultrasound. Ultrasound Med Biol. 2000;26:153-9.

22. Lafon C, Moore D, Eames MDC, et al. Evaluation of Pseudorandom sonications for reducing cavitation with a clinical neurosurgery HIFU device. IEEE Trans Ultrason Ferroelectr Freq Control. 2021;68:1224-33.

23. Reed JA, Bailey MR, Nakazawa M et al. Separating nonlinear propagation and cavitation effects in HIFU. In Ultrasonics, 2003 IEEE Symposium on. IEEE; 2003:728-31

24. Sapozhnikov OA, Khokhlova VA, Bailey M, et al. Effect of overpressure and pulse repetition frequency on cavitation in shock wave lithotripsy. J Acoust Soc Am. 2002;112:1183-95.

25. Bailey MR, Couret LN, Sapozhnikov OA, et al. Use of overpressure to assess the role of bubbles in focused ultrasound lesion shape in vitro. Ultrasound Med Biol. 2001;27:695-708.

26. He M, Zhong Z, Li X, et al. Effects of different hydrostatic pressure on lesions in ex vivo bovine livers induced by high intensity focused ultrasound. Ultrason Sonochem. 2017;36:36-41.

27. Caupin F, Herbert E. Cavitation in water: a review. C R Phys. 2006;7:1000-17.

28. Kinjo T, Matsumoto M. Cavitation processes and negative pressure. Fluid Phase Equilib. 1998;144:343-50.

29. Saito T, Soetanto K. Study on relationship between amount of dissolved oxygen and quantity of microbubbles by ultrasound exposure. Collection of acoustics society studies in Japan. 1998, 1998.

30. Tuziuti T, Hatanaka S, Yasui K, et al. Influence of dissolved oxygen content on multibubble sonoluminescence with ambient-pressure reduction. Ultrasonics. 2002;40:651-4.

31. Xu LS, Shen CF. Clinical observation on the treatment of liver cancer with high intense focused ultrasonic (HIFU) apparatus. J Qilu Oncol. 2005;12:1505-7.

32. Wong SH, Ergun AS, Yaralioglu GG, et al. Design of HIFU CMUT Arrays for Treatment of Liver and Renal Cancer. In International Symposium on Therapeutic Ultrasound. 2007:54-60.

33. Ohto M, Fukuda H, Ito R et al. Contrast-enhanced three dimensional ultrasonography supporting HIFU treatment of small liver cancer. 2009, 1113:86-90

34. Sammet S, Partanen A, Yousuf A, Wardrip C, Niekrasz M, Antic T, Razmaria A, Sokka S, Karczmar G, Oto A. Prostate tissue ablation with MRI guided transurethral therapeutic ultrasound and intraoperative assessment of the integrity of the neurovascular bundle. In International Symposium on Therapeutic Ultrasound. 2017:160004.

35. Liu Y, Liu W, Song Y, Zeng Z. Effects of carboprost tromethamine on HIFU ablation of uterine fibroid. Chongqing Medicine. 2016;45:3949-53.

36. (SFDA) SFDA. High intensity focused ultrasound therapy system. In Volume YY 0592-2005; 2006

37. Mclaughlan J, Rivens I, Ter Haar G. Cavitation detection in ex vivo bovine liver tissue exposed to high intensity focused ultrasound (HIFU). In IEEE International Symposium on Biomedical Imaging: From Nano To Macro. 2007:1124-7.

38. Bailey MR, Khokhlova VA, Sapozhnikov OA, et al. Physical mechanisms of the therapeutic effect of ultrasound (a review). Acoust Phys. 2003:49:369-88.

39. Gielen B, Jordens J, Janssen J, et al. Characterization of stable and transient cavitation bubbles in a milliflow reactor using a multibubble sonoluminescence quenching technique. Ultrason Sonochem. 2015;25:31-9.

40. Peng $S$, Xiong Y, Li K, et al. Clinical utility of a microbubble-enhancing contrast ("SonoVue") in treatment of uterine fibroids with high intensity focused ultrasound: a retrospective study. Eur J Radiol. 2012;81:3832-8.

41. Rabkin BA, Zderic V, Vaezy S. Hyperecho in ultrasound images of HIFU therapy: involvement of cavitation. Ultrasound Med Biol. 2005;31:947-56.

42. Wu J, Nyborg WL. Ultrasound, cavitation bubbles and their interaction with cells. Adv Drug Deliv Rev. 2008:60:1103-16.

\section{Publisher's Note}

Springer Nature remains neutral with regard to jurisdictional claims in published maps and institutional affiliations. 